\title{
Post-abortion initiation of long-acting reversible contraception in New Zealand
}

\author{
Sally B Rose, ${ }^{1}$ Susan M Garrett ${ }^{2}$
}

${ }^{1}$ Senior Research Fellow, Department of Primary Health Care and General Practice, University of Otago, Wellington, New Zealand

${ }^{2}$ Research Fellow, Department of Primary Health Care and General Practice, University of Otago, Wellington, New Zealand

\section{Correspondence to}

Dr Sally B Rose, Department of Primary Health Care and General Practice, University of Otago, Wellington, PO Box 7343, Wellington South 6242 , New Zealand;

sally.rose@otago.ac.nz

Received 13 July 2014 Revised 14 December 2014 Accepted 13 February 2015 Published Online First 8 April 2015

\section{CrossMark}

\footnotetext{
To cite: Rose SB, Garrett SM. J Fam Plann Reprod Health Care 2015:41:197-204.
}

\begin{abstract}
Background Post-abortion initiation of longacting reversible contraception (LARC) reduces subsequent abortion rates within 24 months, but the prevalence of post-abortion LARC use in New Zealand is unknown.
\end{abstract}

Aim To describe post-abortion initiation of intrauterine and implantable LARC methods in New Zealand between 2007 and 2012, and to determine what impact the introduction of government-funded (free) levonorgestrel (LNG) implants in August 2010 had on overall LARC use. Design and setting Retrospective observational study involving New Zealand abortion clinic data.

Methods Nationally collated data on post-abortion LARC insertions were obtained for the period 2007-2012, and individual-level discharge data for patients attending a large urban hospital abortion clinic were analysed using descriptive statistics to describe annual uptake rates, and the demographic profile of LARC users during this period. Logistic regression analyses examined whether LARC use differed by parity and/or age over time.

Results Post-abortion LARC use increased from $20.2 \%$ in 2007 to $45.6 \%$ in 2012 . Intrauterine device use increased from $20.2 \%$ to $31.8 \%$ during this period, with implants contributing a further $14 \%$ to the overall use of LARC methods by 2012. Clinic data showed that LARC use increased among most demographic subgroups between 2009 and 2012 , with the greatest increase among nulliparous under-20-year-olds (from $17.2 \%$ to $42.0 \%$ ).

Conclusions Post-abortion LARC use has been steadily increasing in New Zealand since 2007. Overall LARC use significantly increased following the introduction of government-funded implants, particularly among young and nulliparous women. Improving access to alternative methods of LARC may further increase uptake and reduce unwanted pregnancy rates.

\section{INTRODUCTION}

New Zealand has high rates of unplanned pregnancy and abortion compared to other developed countries, ${ }^{1}$ but has seen a gradual decline in abortions numbers since 2008. The number of abortions

\section{Key message points}

- New Zealand has high rates of unplanned pregnancy and abortion compared to other developed countries, but rates have gradually been declining since 2008.

- The introduction of government-funded levonorgestrel contraceptive implants in 2010 contributed to higher overall rates of post-abortion long-acting reversible contraception (LARC) use, with the greatest increases among younger and nulliparous women.

- Removal of cost barriers to LARC methods can significantly improve uptake, and is likely to reduce rates of unintended pregnancy.

dropped from 17940 in 2008 to 14745 in 2012, with a corresponding drop in the abortion rate (abortions per 1000 women aged 15-44 years) from 19.7 in 2008 to 16.1 in $2012 .^{2}{ }^{3}$ The most dramatic decline has been observed among those aged 19 years and younger. ${ }^{3}$ A declining rate of abortions has also been reported in the USA for the period 2008-2011. ${ }^{4}$ The reason(s) for this decline have not yet been fully explored in New Zealand, but may in part be due to factors such as sexuality education, youth-focused services and improved access to low/no-cost long-acting reversible contraception (LARC). ${ }^{35}$

Internationally, there has been an increasing awareness of the wide-ranging benefits of long-acting reversible contraceptive methods, often referred to as 'LARC' ${ }^{6}$ LARC methods provide the most effective, cost-effective, userindependent way for women to avoid unintended pregnancy and its consequences. $^{7-13}$ These methods do not rely on user adherence for efficacy, are safe 
for use by young and nulliparous women, and once in place they provide protection for 3-5 years and beyond. ${ }^{14}$ The intrauterine device (IUD) was once regarded as appropriate only for women who had completed their families and who were at low-risk for sexually transmitted infections, but is now recommended for all women wanting effective long-term protection against pregnancy, including young and nulliparous women. ${ }^{15}$ A growing number of studies have shown that use of a LARC method significantly reduces rates of unintended pregnancy, rapid repeat adolescent pregnancy and abortion. ${ }^{7} 810111617$

Worldwide, $14.3 \%$ of reproductive-age women use intrauterine methods but rates vary markedly between countries. ${ }^{18}$ A 2014 United Nations report reveals IUDs are used by only $1 \%$ of Canadian women $(2002$ data), 5.2\% of women in the USA (2006-2010 data), $10 \%$ in the UK (2008-2009 data) and $40.6 \%$ of women in China (2006 data). ${ }^{19}$ A small populationbased study conducted in 2003 in New Zealand reported that among 2052 sexually active women aged 18-49 years who were currently using contraception, $11 \%$ were using an IUD. ${ }^{20}$ Population LARC use is dependent on a range of factors at the policy and provider level including availability of products, costrelated issues (device and insertion costs and the complex nature of insurance coverage in some countries), local guidelines on labelling and criteria for use, as well as the availability of trained health providers willing to provide these methods. ${ }^{13} 18$ Women's views and attitudes towards these methods may be influenced by a wide range of factors and are also an important determinant of LARC uptake. ${ }^{21} 22$

Four LARC methods are available for use in New Zealand including two intrauterine methods - the Multiload ${ }^{\circledR} \mathrm{Cu} 375$ (Cu-IUD) and Mirena ${ }^{\circledR}$ levonorgestrel-releasing intrauterine system (LNG-IUS) - and two subdermal implants - the two-rod Jadelle ${ }^{\circledR}$ LNG-releasing implant and single-rod Implanon ${ }^{\circledR}$ etonogestrel (ENG)-releasing implant. Access to LARC has historically been, and continues to be, limited by the high upfront costs associated with these methods in New Zealand and elsewhere. ${ }^{21} 2324$ The Cu-IUD has been available at no/low cost to women in New Zealand since 1995. In August 2010, the LNG implant also became subsidised, and is now available at no or low cost. This change in funding reportedly resulted in a rapid rise in the numbers of women using this method, with 38000 women having received an LNG implant by $2013 .^{25}$ The LNG-IUS and ENG implant still cost upwards of NZ\$300 for device and insertion costs. Anecdotally, these 'non-funded' LARC methods are less frequently prescribed; however, the prevalence of LARC use in New Zealand is not currently known. A range of shorteracting methods (selected oral contraceptives, depot medroxyprogesterone acetate and condoms) are also subsidised in New Zealand.
The present study aimed to describe changes in post-abortion LARC initiation in New Zealand and the impact the introduction of government-funded (free) LNG implants had on the overall uptake of LARC methods. National post-abortion LARC use was described for the years 2007-2012, and data from a large public hospital abortion clinic analysed to describe any changes in the demographic profile of women choosing LARC methods prior to, and following, the availability of funded contraceptive implants.

\section{METHODS}

\section{Design and setting}

This cross-sectional study collected data from two sources: aggregated national data from Statistics New Zealand on numbers of IUDs and implants inserted at the time of an elective induced abortion between 2007 and 2012; and clinic data relating to abortions carried out at a large public hospital abortion clinic in Wellington, New Zealand between January 2007 and December 2012. Abortion is legal in New Zealand up to 19 weeks providing two certifying consultants agree that one of several grounds are met - most commonly 'danger to mental health'. ${ }^{3}$ Abortion is provided as a free health care service for New Zealand residents.

Ethical approval was granted by the University of Otago Human Ethics Committee (12 February 2013, Ref. 12-345) and permission to conduct the research given by the Capital and Coast District Health Board (CCDHB) Women's Health Service Clinical Audit and Research Committee (11 February 2013).

\section{Data collection}

Statistics New Zealand analyse data provided by law to the Abortion Supervisory Committee (ASC) for all abortions in New Zealand. Receipt of an IUD at the time of an abortion has been routinely recorded in the ASC dataset since 2007 and receipt of an implant since 2011. Total numbers of IUDs and implants inserted annually were provided by Statistics New Zealand (no demographic data were provided). To obtain a demographic description of LARC users, data were drawn from electronic discharge records at the CCDHB abortion clinic. This is the second largest of 23 abortion services in New Zealand, ${ }^{3}$ providing a first- and second-trimester abortion service and offering surgical and medical abortion. Patient-centred contraceptive counselling is provided prior to the procedure and women are encouraged to have a contraceptive plan in place at discharge. Three LARC methods can be initiated prior to discharge: a Cu-IUD or LNG-IUS for women presenting for first-trimester surgical abortion (eligibility is determined on a case-by-case basis for second-trimester abortion) or LNG implants, which were only available to women having a surgical abortion. The ENG implant was not available at this clinic (primarily due to cost). At the time of data collection women undergoing medical 
abortion were not eligible for same-day LARC (they are now eligible), but could have opted for a surgical procedure had they wanted to initiate a LARC method prior to discharge.

Electronically collected data for all hospital clinic attendees between 2009 and 2012 included age, date and method of procedure, gestational age, previous pregnancy history and National Health Index number (NHI, a unique patient identifier). ${ }^{26}$ Contraceptive method use was collected from a paper notebook kept by clinic staff to identify those women who received a LARC method on the day of their abortion (recorded against NHI). Data on LARC insertions by age-band (only) were also collated for the years 2007-2008. NHI data were matched by Analytical Services (Ministry of Health) to obtain ethnicity and NZDeprivation (NZDep06). Ethnicity refers to the ethnic group to which an individual belongs and is collected via self-report using the standardised New Zealand 2001 census question. ${ }^{27}$ Ethnicity was re-categorised into the following broad groups: European, Maori, Pacific, Asian, MELAA (Middle Eastern, Latin American/Hispanic, African) and Not known/Other based on prioritised ethnicity for individuals reporting multiple ethnicities as per Ministry of Health guidelines. ${ }^{28}$ NZDep06 is a validated, censusderived, area-based index of deprivation, measured on an ordinal scale from 1 to 10 , where 1 represents least deprived areas and 10 most deprived areas. ${ }^{29}$

\section{Statistical analyses}

Numbers of LARC insertions (IUD or implant) were presented as a proportion of the total number of women undergoing an abortion in New Zealand for the years 2007-2012. 'IUD' includes both Cu-IUD and LNG-IUS. LARC use at a single abortion clinic was collated by age-band for the years 2007-2012, and tabulated by demographic and clinical characteristics for the year 2009 - prior to the introduction of free LNG implants - and also for 2012 (18 months following their introduction). Logistic regression analyses were performed to examine whether changes in total LARC use over time differed by parity and/or age. Year $(2009,2012)$, age (5-year bands) and parity ( 0 or $1+)$ were included in the model, and odds ratios (ORs) and 95\% confidence intervals (CIs) reported to describe the magnitude of any changes over time.

\section{RESULTS}

\section{Post-abortion LARC use in New Zealand}

Figure 1 shows numbers of women initiating same-day LARC at the time of an abortion in New Zealand between 2007 and 2012, with total LARC use shown as a proportion. Abortion numbers declined during this period (from 18382 in 2007 to 14745 in 2012) and the proportion of women using LARC methods steadily increased from $20.2 \%$ in $2007(n=3721)$ to more than twice that proportion by $2012(45.6 \%, n=6729)$. The proportions of women receiving an IUD declined slightly from 2011 with the availability of funded LNG implants. The absolute increase in LARC use with each consecutive year showed a steadily increasing rate of use over time, but with the biggest increase (6.9\%) between 2011 and 2012 coinciding with the availability of (free) LNG implants.

\section{Post-abortion LARC use at a single abortion clinic}

Table 1 presents the proportion of women receiving same-day placement of a LARC method at a single public hospital abortion clinic between 2007 and 2012, presented by age-band. Total LARC use for the years 2007-2009 includes IUDs only. For the year 2010 total LARC use also includes implants, which became available in August 2010. LARC uptake at this

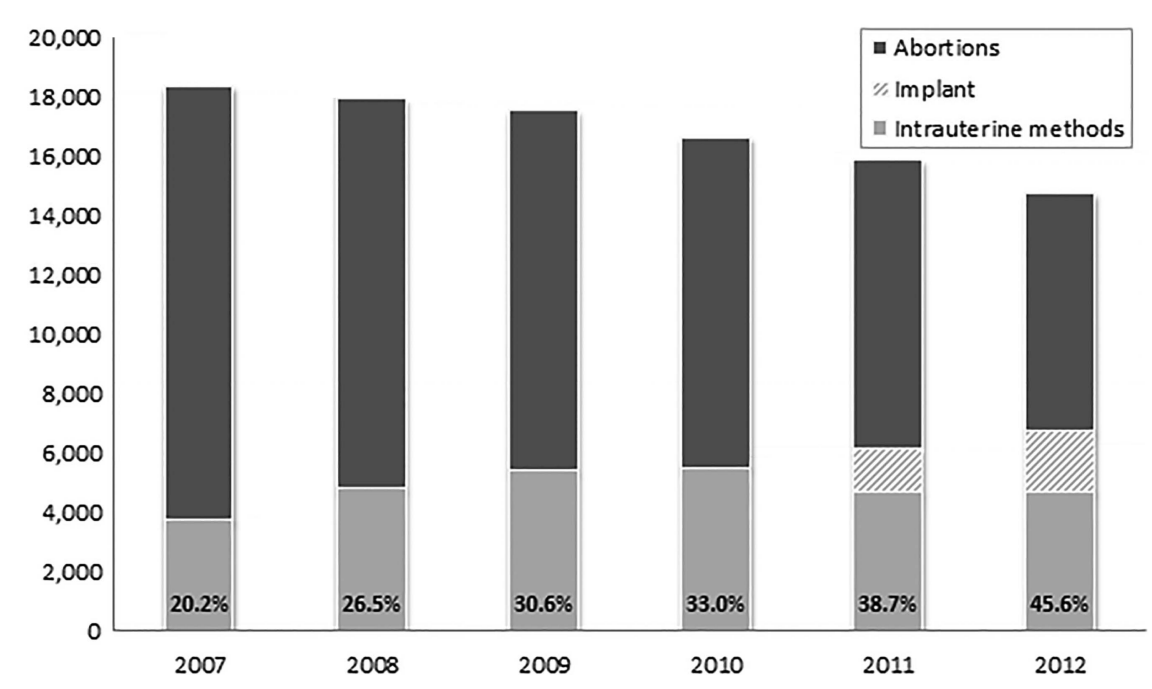

Figure 1 Numbers of women undergoing abortion throughout New Zealand between 2007 and 2012, and same-day initiation of long-acting reversible contraception (LARC) (total LARC use is shown as a percentage). 
Table 1 Proportion and 95\% confidence interval $(\mathrm{Cl})$ of women receiving long-acting reversible contraception at a public hospital abortion clinic for the years 2007-2012, presented by 5-year age-band

\begin{tabular}{|c|c|c|c|c|c|c|c|c|c|c|c|}
\hline \multirow[b]{2}{*}{ Year } & \multirow{2}{*}{$\begin{array}{l}\text { Total } \\
n\end{array}$} & \multicolumn{2}{|c|}{ Age $<20$ years } & \multicolumn{2}{|c|}{ Age $20-24$ years } & \multicolumn{2}{|c|}{ Age $25-29$ years } & \multicolumn{2}{|c|}{ Age $30+$ years } & \multicolumn{2}{|c|}{ All ages } \\
\hline & & $\%$ & $95 \% \mathrm{Cl}$ & $\%$ & $95 \% \mathrm{Cl}$ & $\%$ & $95 \% \mathrm{Cl}$ & $\%$ & $95 \% \mathrm{Cl}$ & $\%$ & $95 \% \mathrm{Cl}$ \\
\hline 2007 & 3062 & 8.3 & $(6.4-10.6)$ & 17.3 & (15.0-19.9) & 24.4 & $(20.9-28.1)$ & 31.2 & $(28.0-34.4)$ & 20.3 & $(18.9-21.8)$ \\
\hline 2008 & 2857 & 14.8 & $(12.2-17.9)$ & 30.5 & $(27.6-33.5)$ & 31.1 & $(27.3-35.1)$ & 35.9 & $(32.4-39.6)$ & 28.5 & $(26.8-30.2)$ \\
\hline 2009 & 2771 & 21.5 & $(18.4-24.9)$ & 34.5 & $(31.3-37.7)$ & 40.8 & $(36.7-45.0)$ & 43.6 & (39.9-47.5) & 34.9 & $(33.2-36.7)$ \\
\hline 2010 & 2687 & 25.9 & $(22.3-29.6)$ & 40.7 & $(37.4-44.0)$ & 42.3 & $(38.1-46.5)$ & 42.6 & $(38.9-46.5)$ & 38.3 & $(36.4-40.1)$ \\
\hline 2011 & 2499 & 45.0 & $(40.6-49.5)$ & 45.3 & $(42.1-48.5)$ & 47.1 & $(42.5-51.7)$ & 44.6 & $(40.6-48.7)$ & 45.4 & $(43.5-47.4)$ \\
\hline 2012 & 2218 & 46.0 & $(41.2-51.0)$ & 52.1 & $(48.4-55.8)$ & 50.4 & $(45.8-55.0)$ & 47.8 & $(43.7-51.9)$ & 49.5 & $(47.4-51.6)$ \\
\hline
\end{tabular}

clinic was similar to that at the national level in both 2007 (20.3\% vs 20.2 nationally) and 2012 (49.5\% vs $45.6 \%$ nationally). The proportion of young women (aged $<20$ years) receiving an IUD has been steadily increasing over time, from $8.3 \%$ in 2007 to $21.5 \%$ by 2009 - the year before implants were available at the clinic. From 2007 to 2012 there was a five-fold increase in LARC use by under-20-year-olds. In 2007, there were significant differences in LARC use by age-band $(8.3 \%$ vs $31.2 \%$ for $<20$ years and $30+)$, but by 2012 there was little difference in LARC use by age ( $46 \%$ vs $47.8 \%)$.

\section{Impact of funded contraceptive implants on LARC use}

Table 2 presents the characteristics of women choosing same-day insertion of LARC method at a hospital abortion clinic in the years 2009 and 2012 (before and after the availability of contraceptive implants). In 2009 the proportion of women receiving a LARC method increased with increasing age, but by 2012 close to half $(43-52 \%)$ of all women received a LARC method regardless of age. The proportion of nulliparous women receiving a LARC method in 2009 was $24 \%$, increasing to $44 \%$ by 2012 . A higher proportion of women presenting in the second trimester were able to initiate a LARC method in 2012 than in 2009 , with implants routinely available to women in the second trimester, but IUDs considered on a case-by-case basis. There was little change in the demographic profile of IUD users in the comparison years, but overall use of a LARC method increased from $34.9 \%$ in 2009 to $49.5 \%$ in 2012 with the addition of implants.

Table 3 presents the data from the single clinic on LARC use in 2009 and 2012 by age and parity, with 95\% CIs. ORs (and 95\% CIs) estimate the change in LARC uptake over time according to age and parity (estimated from logistic regression). Under-20-yearolds who had one or more previous births at the time of an abortion became the highest users of a LARC method once implants were available (65\%). Type 3 analysis of effects tests showed significant effects of year, parity and age $(p<0.01)$ and a significant interaction between year and parity $(p=0.04)$ and year and age $(p<0.01)$. The three-way interaction test for year, age and parity was not significant $(p>0.05)$. ORs presented in Table 3 represent the size of the shift in the proportion choosing a LARC method from 2009 to 2012. The largest increase in the odds of postabortion LARC use in 2012 compared with 2009 was among nulliparous under-20-year-olds (OR 3.3, 95\% CI 2.5-4.4). The magnitude of change between the two time periods declined with increasing age, regardless of parity.

\section{DISCUSSION}

Post-abortion LARC use has steadily increased in New Zealand, with more than double the proportion of women using a LARC in 2012 compared with 2007. IUDs have become more popular and the availability of government-funded contraceptive implants from late 2010 further contributed to the overall increase in LARC use. Data drawn from the single clinic showed that teenagers were two and a half times more likely to receive an IUD by $2009(21.5 \%)$ compared with 2007 (8.3\%). When comparing uptake before and after free implant availability, the biggest increase in LARC use was seen among nulliparous under-20-year-olds.

\section{Strengths and limitations}

This study is the first to report on same-day postabortion LARC use in New Zealand. The two sources of data (national and clinic-level) showed good overall correlation. Patients at the participating clinic were demographically similar to women presenting for abortion nationwide, ${ }^{3}$ so patterns of LARC use at this clinic may reflect patterns occurring nationally. One factor known to have contributed to an increase in LARC use at the clinic was an intervention study that ran for 10 weeks in September 2008. The intervention offered LARC methods at no cost, counselling highlighted the benefits of LARC, and staff were provided with updated information about the suitability of IUDs for young and nulliparous women. ${ }^{30}$ The uptake of IUDs increased significantly during this intervention from $24.3 \%$ to $47.6 \%$, largely due to the increase in uptake of free LNG-IUS (increasing from 
Table 2 Patient characteristics and proportions initiating post-abortion long-acting reversible contraception at a public hospital abortion clinic in 2009 and 2012

\begin{tabular}{|c|c|c|c|c|c|c|c|c|c|c|}
\hline \multirow[b]{3}{*}{ Patient characteristics } & \multicolumn{3}{|c|}{2009 (implants unavailable) } & \multicolumn{7}{|c|}{2012 (subsidised implants available) } \\
\hline & \multirow{2}{*}{$\begin{array}{l}\text { Total } \\
\text { sample } \\
n\end{array}$} & \multicolumn{2}{|c|}{$\begin{array}{l}\text { Intrauterine } \\
\text { methods* } \\
\text { (total LARC) }\end{array}$} & \multirow{2}{*}{$\begin{array}{l}\text { Total } \\
\text { sample } \\
n\end{array}$} & \multicolumn{2}{|c|}{$\begin{array}{l}\text { Intrauterine } \\
\text { methods }\end{array}$} & \multicolumn{2}{|c|}{ Implant } & \multicolumn{2}{|c|}{ Total LARC } \\
\hline & & $n$ & $\%$ & & $n$ & $\%$ & $n$ & $\%$ & $n$ & $\%$ \\
\hline Total LARC use & 2771 & 968 & 34.9 & 2218 & 734 & 33.1 & 363 & 16.3 & 1097 & 49.5 \\
\hline \multicolumn{11}{|l|}{ Age-band (years) } \\
\hline $13-15$ & 29 & 6 & 20.7 & 28 & 5 & 17.9 & 7 & 25.0 & 12 & 42.9 \\
\hline $16-19$ & 622 & 134 & 21.5 & 387 & 87 & 22.5 & 92 & 23.8 & 179 & 46.3 \\
\hline $20-24$ & 888 & 306 & 34.5 & 735 & 243 & 33.1 & 140 & 19.0 & 383 & 52.1 \\
\hline $25-29$ & 556 & 227 & 40.8 & 480 & 169 & 35.2 & 73 & 15.2 & 242 & 50.4 \\
\hline $30-34$ & 321 & 137 & 42.7 & 302 & 115 & 38.1 & 37 & 12.3 & 152 & 50.3 \\
\hline $35-39$ & 236 & 104 & 44.1 & 198 & 71 & 35.9 & 13 & 6.6 & 84 & 42.4 \\
\hline $40+$ & 119 & 54 & 45.4 & 88 & 44 & 50.0 & 1 & 1.1 & 45 & 51.1 \\
\hline \multicolumn{11}{|l|}{ Ethnic group } \\
\hline NZ European & 1304 & 418 & 32.1 & 1075 & 345 & 32.1 & 155 & 14.4 & 500 & 46.5 \\
\hline NZ Maori & 796 & 300 & 37.7 & 658 & 207 & 31.5 & 155 & 23.6 & 362 & 55.0 \\
\hline Pacific & 311 & 122 & 39.2 & 256 & 105 & 41.0 & 41 & 16.0 & 146 & 57.0 \\
\hline Asian & 254 & 99 & 39.0 & 192 & 68 & 35.4 & 8 & 4.2 & 76 & 39.6 \\
\hline MELAA & 37 & 5 & 13.5 & 23 & 7 & 30.4 & 2 & 8.7 & 9 & 39.1 \\
\hline Not known/other & 69 & 24 & 34.8 & 14 & 2 & 14.3 & 2 & 14.3 & 4 & 28.6 \\
\hline \multicolumn{11}{|l|}{ SES/deprivation level† } \\
\hline Dep 1-3 (least) & 516 & 178 & 34.5 & 421 & 140 & 33.3 & 48 & 11.4 & 188 & 44.7 \\
\hline Dep 4-7 (medium) & 1045 & 369 & 35.3 & 813 & 269 & 33.1 & 136 & 16.7 & 405 & 49.8 \\
\hline Dep 8-10 (most) & 1210 & 421 & 34.8 & 981 & 324 & 33.0 & 178 & 18.1 & 502 & 51.2 \\
\hline \multicolumn{11}{|l|}{ Abortion procedure } \\
\hline Surgical & 2608 & 968 & 37.1 & 2119 & 734 & 34.6 & 363 & 17.1 & 1097 & 51.8 \\
\hline Medical & 163 & 0 & 0 & 101 & 0 & 0 & 0 & 0 & 0 & 0 \\
\hline \multicolumn{11}{|l|}{ Trimester } \\
\hline First & 2589 & 952 & 36.8 & 2070 & 713 & 34.4 & 337 & 16.3 & 1050 & 50.7 \\
\hline Second & 182 & 16 & 8.8 & 148 & 21 & 14.2 & 26 & 17.6 & 47 & 31.8 \\
\hline \multicolumn{11}{|l|}{ Previous abortion(s) } \\
\hline 0 & 1696 & 521 & 30.7 & 1304 & 394 & 30.2 & 204 & 15.6 & 598 & 45.9 \\
\hline 1 & 693 & 275 & 39.7 & 586 & 213 & 36.3 & 99 & 16.9 & 312 & 53.2 \\
\hline 2 & 229 & 93 & 40.6 & 207 & 73 & 35.3 & 38 & 18.4 & 111 & 53.6 \\
\hline $3+$ & 153 & 79 & 51.6 & 121 & 54 & 44.6 & 22 & 18.2 & 76 & 62.8 \\
\hline \multicolumn{11}{|l|}{ Parity } \\
\hline 0 & 1446 & 344 & 23.8 & 1002 & 275 & 27.4 & 151 & 15.1 & 426 & 42.5 \\
\hline 1 & 531 & 233 & 43.9 & 484 & 164 & 33.9 & 94 & 19.4 & 258 & 53.3 \\
\hline 2 & 450 & 214 & 47.6 & 391 & 144 & 36.8 & 57 & 14.6 & 201 & 51.4 \\
\hline $3+$ & 344 & 177 & 51.5 & 341 & 151 & 44.3 & 61 & 17.9 & 212 & 62.2 \\
\hline \multicolumn{11}{|l|}{ Gravida } \\
\hline 1 & 1001 & 199 & 19.9 & 709 & 186 & 26.2 & 103 & 14.5 & 289 & 40.8 \\
\hline 2 & 563 & 201 & 35.7 & 409 & 121 & 29.6 & 74 & 18.1 & 195 & 47.7 \\
\hline $3+$ & 1207 & 568 & 47.1 & 1100 & 427 & 38.8 & 186 & 16.9 & 613 & 55.7 \\
\hline
\end{tabular}

*Includes copper intrauterine device and levonorgestrel intrauterine system.

tThree women had missing data on NZDep in 2012 (and were excluded only from this subsection of the table).

Dep, deprivation; LARC, long-acting reversible contraception; MELAA, Middle Eastern, Latin American/Hispanic, African; NZ, New Zealand;

SES, socioeconomic status.

$6 \%$ to $36 \%) .{ }^{30}$ Once the LNG-IUS was no longer free, uptake reverted to baseline levels, but use of a (free) $\mathrm{Cu}-\mathrm{IUD}$ increased after the study, at a magnitude similar to that observed at the national level.
Data on use of subsidised versus non-subsidised methods (LNG-IUS vs Cu-IUD, LNG vs ENG) were not available from the national dataset (they are recorded as 'IUD' or 'implant'), but it is likely that 
Table 3 Change in post-abortion long-acting reversible contraception use from 2009 to 2012 at a public hospital abortion clinic in relation to parity and age

\begin{tabular}{|c|c|c|c|c|c|c|c|c|c|c|}
\hline \multirow[b]{3}{*}{ Parity and age (years) } & \multicolumn{4}{|l|}{2009} & \multicolumn{4}{|l|}{2012} & & \\
\hline & \multirow{2}{*}{$\begin{array}{l}\text { Total } \\
n\end{array}$} & \multicolumn{3}{|c|}{$\begin{array}{l}\text { Total LARC use } \\
\text { (IUD only) }\end{array}$} & \multirow{2}{*}{$\begin{array}{l}\text { Total } \\
n\end{array}$} & \multicolumn{3}{|c|}{$\begin{array}{l}\text { Total LARC use } \\
\text { (IUD and implant) }\end{array}$} & \multicolumn{2}{|c|}{$\begin{array}{l}\text { Logistic } \\
\text { regression }\end{array}$} \\
\hline & & $n$ & $\%$ & $95 \% \mathrm{Cl}$ & & $n$ & $\%$ & $95 \% \mathrm{Cl}$ & OR & $95 \% \mathrm{Cl}$ \\
\hline \multicolumn{11}{|l|}{ Nulliparous } \\
\hline$<20$ & 548 & 94 & 17.2 & $14.1-20.6$ & 343 & 144 & 42.0 & $36.7-47.4$ & 3.3 & $2.5-4.4$ \\
\hline $20-24$ & 544 & 147 & 27.0 & $23.3-31.0$ & 402 & 178 & 44.3 & $39.4-49.3$ & 2.3 & $1.8-2.8$ \\
\hline $25-29$ & 234 & 60 & 25.6 & $20.2-31.7$ & 159 & 64 & 40.3 & $32.6-48.3$ & 1.7 & $1.2-2.3$ \\
\hline $30+$ & 120 & 43 & 35.8 & $27.3-45.1$ & 98 & 40 & 40.8 & $31.0-51.2$ & 1.5 & $1.1-2.0$ \\
\hline \multicolumn{11}{|l|}{ Parity 1+ } \\
\hline$<20$ & 103 & 46 & 44.7 & $34.9-54.8$ & 72 & 47 & 65.3 & $53.1-76.1$ & 2.5 & $1.8-3.6$ \\
\hline $20-24$ & 344 & 159 & 46.2 & $40.9-51.6$ & 333 & 205 & 61.6 & $56.1-66.8$ & 1.7 & $1.3-2.2$ \\
\hline $25-29$ & 322 & 167 & 51.9 & $46.3-57.4$ & 321 & 178 & 55.5 & $49.8-61.0$ & 1.3 & $1.0-1.7$ \\
\hline $30+$ & 556 & 252 & 45.3 & $41.1-49.6$ & 490 & 241 & 49.2 & $44.7-53.7$ & 1.1 & $0.9-1.4$ \\
\hline
\end{tabular}

$\mathrm{Cl}$, confidence interval; IUD, intrauterine device; LARC, long-acting reversible contraception; OR, odds ratio.

the majority of IUDs and implants inserted were the government-funded methods as was the case for the single clinic participating in this study. Data on postabortion implant insertions were not collected in national records until 2011, so total LARC use may be underestimated for prior years. The extent to which other clinics offered implants for post-abortion use before they became subsidised is not known, but is believed to be low. The high costs of non-subsidised methods are cited as barriers to use of these methods by women. $^{21}$ LARC use may have been underreported in the present study due to the design of the data collection form used nationally - a tick box asks clinic staff to indicate that an IUD or implant was inserted. It is not a Yes/No question so the absence of a tick could mean no LARC insertion or in some instances represent missing data. Human error in recording method use at the clinic level may have underestimated or overestimated actual use - requesting patient medical records to cross-check for accuracy was not feasible in the current project.

LARC use in the general population in New Zealand is not known but uptake by women postabortion is likely to be significantly higher for several reasons: abortion services provide comprehensive contraceptive counselling and women are encouraged to have a contraceptive plan in place prior to discharge, and motivation to avoid future unwanted pregnancies may result in a greater likelihood of LARC selection. IUDs and implants can be inserted at the time of the abortion, so do not require a further clinic visit or visits (two or more visits are often required for women in the community). For New Zealand residents, no insertion costs or visit fees are charged for receipt of a (funded) LARC method at the time of an abortion, whereas insertion and consultation costs apply even for subsidised methods in most community health settings.

\section{Implications}

The American College of Obstetricians and Gynecologists recommends that LARC methods be offered and made accessible to all sexually active adolescents for the prevention of unintended pregnancy. ${ }^{13}$ This study suggests that at-risk adolescents are receiving counselling about, as well as access to, LARC methods at the time of an abortion in New Zealand. Government funding for LNG implants from 2010 coincided with a significant increase in post-abortion LARC use among under-20-year-olds. Over $45 \%$ of under-20-year-olds initiated LARC methods, suggesting that contraceptive counselling provided to women at this clinic generally takes into account current recommendations about the suitability of LARC methods, irrespective of age or parity. The lower overall use of LARC methods by nulliparous women (of all ages) might reflect more short-term future pregnancy intent; a higher proportion of parous women presenting for abortion are likely to have completed their families and so might be more likely to opt for a long-term method of contraception.

New Zealand has seen a gradual decline in its annual abortion rates since 2008, particularly among those aged under 20 years. ${ }^{3}$ While the reason(s) for this decline have not yet been explored, it is plausible that improved access to low/no-cost LARC is a contributing factor, especially considering the high rates of implant use noted in younger age groups. It is likely that LARC use has also risen in the general population in New Zealand, but data are needed to estimate the overall contribution of LARC use to the declining abortion rate. The increase from one to two funded LARC methods in New Zealand has had a significant impact on LARC uptake among women undergoing abortion. Extending this access to include all available LARC methods in New Zealand would allow women to choose a method that best suits their 
preferences, and would potentially further decrease the numbers of unintended pregnancies.

Acknowledgements The authors wish to thank Dr James Stanley (Biostatistician, Dean's Department, University of Otago) for advice and assistance with statistical analyses, staff at Capital and Coast District Health Board for assistance with clinic data collection, and Statistics New Zealand for the provision of national data on LARC use.

Funding This study was funded by a University of Otago Research grant.

\section{Competing interests None.}

Ethics approval University of Otago Human Ethics Committee. Provenance and peer review Not commissioned; externally peer reviewed.

\section{REFERENCES}

1 Hutchison P. Inquiry into improving child health outcomes and preventing child abuse, with a focus on preconception until three years of age. 2013. Report of the Health Committee. Presented to the House of Representatives. http://www. parliament.nz/resource/0002018580 [accessed 30 June 2014].

2 Abortion Supervisory Committee. Report of the Abortion Supervisory Committee 2008. Presented to the House of Representatives pursuant to Section 39 of the Contraception, Sterilisation and Abortion Act 1977. New Zealand. 2009. http://www.parliament.nz/resource/0000086956 [accessed 30 June 2014].

3 Abortion Supervisory Committee. Report of the Abortion Supervisory Committee 2013. Presented to the House of Representatives pursuant to Section 39 of the Contraception, Sterilisation and Abortion Act 1977. New Zealand. 2013. http://www.parliament.nz/resource/en-nz/50DBHOH PAP25739_1/224b90a3ac6fd5dde32f5e144a0d0730bf4f1321 [accessed 26 May 2014].

4 Jones RK, Jerman J. Abortion incidence and service availability in the United States, 2011. Perspect Sex Reprod Health 2014;46:3-14.

5 Family Planning New Zealand. Pregnancy and abortion rates drop - disparity still a concern. Forum 2014;3. http://issuu. com/familyplanningnewzealand/docs/forum_march_2014_issuu [accessed 30 June 2014].

6 Hillard PJA. What is LARC? And why does it matter for adolescents and young adults? J Adolesc Health 2013; 52(4 Suppl.):S1-S5.

7 Tocce KM, Sheeder JL, Teal SB. Rapid repeat pregnancy in adolescents: do immediate postpartum contraceptive implants make a difference? Am J Obstet Gynecol 2012;206:481 e481-e487.

8 Stevens-Simon C, Kelly L, Kulick R. A village would be nice but ...: it takes a long-acting contraceptive to prevent repeat adolescent pregnancies. Am J Prev Med 2001;21:60-65.

9 Ames CM, Norman WV. Preventing repeat abortion in Canada: is the immediate insertion of intrauterine devices postabortion a cost-effective option associated with fewer repeat abortions? Contraception 2012;85:51-55.

10 Baldwin MK, Edelman AB. The effect of long-acting reversible contraception on rapid repeat pregnancy in adolescents: a review. J Adolesc Health 2013;52:S47-S53.

11 Peipert JF, Madden T, Allsworth JE, et al. Preventing unintended pregnancies by providing no-cost contraception. Obstet Gynecol 2012;120:1291-1297.
12 Hatcher R, Trussell J, Nelson A, et al. Contraceptive Technology (20th edn). Atlanta, GA: Ardent Media, 2011.

13 American College of Obstetrics and Gynecology (ACOG) Committee. ACOG Committee Opinion No. 450: increasing use of contraceptive implants and intrauterine devices to reduce unintended pregnancy. Obstet Gynecol 2009;114:1434-1438.

14 National Collaborating Centre for Women's and Children's Health. Long-acting Reversible Contraception: The Effective and Appropriate Use of Long-acting Reversible Contraception. Commissioned by the National Institute for Health and Clinical Excellence, 2005. http://www.nice.org.uk/guidance/ cg30/evidence/cg30-longacting-reversible-contraception-fullguideline3 [accessed 30 June 2014].

15 Committee on Adolescent Health Care Long-Acting Reversible Contraception Working Group, The American College of Obstetricians and Gynecologists. Committee opinion no. 539: adolescents and long-acting reversible contraception: implants and intrauterine devices. Obstet Gynecol 2012;120:983-988.

16 Langston AM, Joslin-Roher SL, Westhoff CL. Immediate postabortion access to IUDs, implants and DMPA reduces repeat pregnancy within 1 year in a New York City practice. Contraception 2014;89:103-108.

17 Rose SB, Lawton BA. Impact of long-acting reversible contraception on return for repeat abortion. Am J Obstet Gynecol 2012;206:37.e31-37.e36.

18 Buhling KJ, Zite NB, Lotke P, et al. Worldwide use of intrauterine contraception: a review. Contraception 2014;89:162-173.

19 United Nations: World Contraceptive Use 2014. Department of Economic and Social Affairs, Population Division 2014, (POP/DB/CP/Rev2014). http://www.un.org/en/development/ $\mathrm{desa} /$ population/publications/dataset/contraception/wcu2014. shtml [accessed 11 November 2014].

20 Fanslow J, Whitehead A, Silva M, et al. Contraceptive use and associations with intimate partner violence among a population-based sample of New Zealand women. Aust N Z J Obstet Gynaecol 2008;48:83-89.

21 Rose SB, Cooper AJ, Baker NK, et al. Attitudes towards longacting reversible contraception among young women presenting for abortion. J Women's Health 2011;20:1729-1735.

22 Glasier A, Scorer J, Bigrigg A. Attitudes of women in Scotland to contraception: a qualitative study to explore the acceptability of long-acting methods. J Fam Plann Reprod Health Care 2008;34:213-217.

23 Secura GM, Allsworth JE, Madden T, et al. The Contraceptive CHOICE Project: reducing barriers to long-acting reversible contraception. Am J Obstet Gynecol 2010;203:115.e1-115.e7.

24 Eisenberg D, McNicholas C, Peipert JF. Cost as a barrier to long-acting reversible contraceptive (LARC) use in adolescents. J Adolesc Health 2013;52(4 Suppl.):S59-S63.

25 Medsafe (New Zealand Medicines and Medical Devices Safety Authority). Removal difficulties with Jadelle and Implanon. Prescriber Update 2013;34:27-28. http://www.medsafe.govt.nz/ profs/PUArticles/Sept2013JadelleandImplanon.htm [accessed 11 November 2013].

26 New Zealand Health Information Service. National Health Index. Wellington, New Zealand: Ministry of Health, 2010. http://www.health.govt.nz/our-work/health-identity/nationalhealth-index [accessed 12 September 2013].

27 Statistics New Zealand. Ethnicity Definition. Wellington, New Zealand. 2006. http://www.stats.govt.nz/methods/ classifications-and-standards/classification-related- 


\section{Article}

stats-standards/ethnicity/definition.aspx [accessed 30 June 2014].

28 Ministry of Health. Ethnicity Data Protocols for the Health and Disability Sector. Wellington, New Zealand: Ministry of Health, 2004. https:/www.health.govt.nz/system/files/ documents/publications/ethnicitydataprotocols.pdf [accessed 30 June 2014].
29 Salmond C, Crampton P, Aitkenson J. NZDep2006 Index of Deprivation. User's Manual. Wellington, New Zealand: Department of Public Health, University of Otago, 2007:1-16. http://www. otago.ac.nz/wellington/otago020337.pdf [accessed 30 June 2014].

30 Rose SB, Lawton BA, Brown SA. Uptake and adherence to long-acting reversible contraception post-abortion. Contraception 2010;82:345-353. 